\title{
Strength deficit of knee flexors is dependent on hip position in adults with chronic hemiparesis
}

\author{
Stella M. Michaelsen ${ }^{1}$, Angélica C. Ovando ${ }^{1}$, Adriano Bortolotti ${ }^{2}$,
} Bruno Bandini ${ }^{2}$

\begin{abstract}
Background: The extent to which muscle length affects force production in paretic lower limb muscles after stroke in comparison to controls has not been established. Objectives: To investigate knee flexor strength deficits dependent on hip joint position in adults with hemiparesis and compare with healthy controls. Method: a cross-sectional study with ten subjects with chronic ( $63 \pm 40$ months) hemiparesis with mild to moderate lower limb paresis (Fugl-Meyer score $26 \pm 3$ ) and 10 neurologically healthy controls. Isometric knee flexion strength with the hip positioned at $90^{\circ}$ and $0^{\circ}$ of flexion was assessed randomly on the paretic and non-paretic side of hemiparetic subjects and healthy controls. Subjects were asked to perform a maximal isometric contraction sustained for four seconds and measured by a dynamometer. The ratio of knee flexor strength between these two hip positions was calculated: Hip $0^{\circ} / \mathrm{Hip} 90^{\circ}$. Also, locomotor capacity was evaluated by the timed up and go test and by walking velocity over 10 meters. Results: In subjects with hemiparesis, absolute knee flexion torque decreased $(\mathrm{p}<0.001)$ with the hip in extension $\left(\right.$ at $\left.0^{\circ}\right)$. The ratio of knee flexor torque Hip $0^{\circ} / \mathrm{Hip} 90^{\circ}$ on the paretic side in hemiparetics was lower than in controls $(\mathrm{p}=0.02)$. Conclusions: Weakness dependent on joint position is more significant in the paretic lower limb of adults with hemiparesis when compared to controls. More attention should be given to lower limb muscle strengthening exercises in individuals with stroke, with emphasis on the strengthening exercises in positions in which the muscle is shortened.
\end{abstract}

Keywords: stroke; lower extremity; muscle weakness; physical therapy; rehabilitation.

\section{HOW TO CITE THIS ARTICLE}

Michaelsen SM, Ovando AC, Bortolotti A, Bandini B. Strength deficit of knee flexors is dependent on hip position in adults with chronic hemiparesis. Braz J Phys Ther. 2013 Jan-Feb; 17(1):86-91. http://dx.doi.org/10.1590/S1413-35552012005000070

\section{Introduction}

After a stroke, individuals often show clinical symptoms such as spasticity, weakness, loss of selective control and altered muscle coactivation patterns ${ }^{1-3}$. Among these symptoms, muscle weakness is an important factor in disturbing the voluntary movements in persons with unilateral brain injury, and it is recognized as a major problem contributing to disability after stroke ${ }^{3}$.

Muscles can generate more force in a lengthened position than in a shortened position. This increase in force production has been demonstrated in muscles of healthy subjects, in general, and in healthy hamstring muscles, in particular ${ }^{4,5}$. Weakness dependent on joint position in subjects with hemiparesis was largely described for upper extremity ${ }^{3,6}$. Despite a large number of studies considering this question for upper extremities ${ }^{6-9}$, less attention has been given to describing the effect of joint position on lower limb force production after stroke.

The extent to which muscle length affects force production in paretic lower limb muscles has not been established. Nonetheless, clinicians who treat hemiparetic patients and researchers are well aware of the difficulty that these patients have in performing knee flexion with the hip extended in comparison to knee flexion with the hip flexed, when the muscle is at a greater length.

A previous study from Bohannon ${ }^{10}$ addresses this question, but it did not include chronic stroke subjects in its sample and it did not include healthy controls. Furthermore, no study has reported a decrease in isometric knee flexion force in chronic subjects compared to controls. Thus, the main objectives of this study were: (1) to evaluate the loss in maximum isometric voluntary knee flexion torque production that is dependent on muscle length (hip position) in paretic and non-paretic lower limb (LL) of subjects with hemiparesis (2) to evaluate the loss in maximum isometric voluntary knee flexion torque production that is dependent on muscle length (hip position) in dominant and non-dominant lower limbs in healthy controls, and (3) to compare the hip $0^{\circ} /$ hip $90^{\circ}$ ratio

${ }^{1}$ Center of Health and Sports Sciences, Universidade do Estado de Santa Catarina (UDESC), Florianopolis, SC, Brazil

${ }^{2}$ School of Physical Therapy, Universidade Luterana Brasileira (ULBRA), Canoas, RS, Brazil

Received: 09/11/2012 Revised: 09/25/2012 Accepted: 10/12/2012 
of maximum isometric voluntary knee flexion torque production (the ratio of knee flexion torque between hip extended and hip flexed) of the paretic lower limb in subjects with hemiparesis with non-paretic limb and with aged matched controls.

\section{Method}

\section{Subjects}

Ten subjects with hemiparesis, $59 \pm 5.4$ years (range 51-65) and 10 healthy subjects, $60 \pm 8.8$ years participated after signing informed consent forms approved by the Ethics Committee of Universidade Luterana Brasileira (ULBRA), Canoas, RS, Brazil, protocol no. 2006-024H. Persons with hemiparesis had suffered a single non-traumatic unilateral stroke $63 \pm 40$ months previously. All participants could understand simple instructions and were able to walk 10 meters without assistance. Those with pain or other neurological or orthopedic conditions affecting the lower limb, passive range of movement for knee flexion less than $100^{\circ}$, or hip deformity in flexion were excluded. The healthy group consisted of age matched individuals without neuromuscular or neurological problems affecting the lower limb.

\section{Clinical evaluation}

Prior to data collection, all subjects with hemiparesis underwent a series of clinical tests administered by an experienced physical therapist who evaluated the status of their paretic lower limb (LL) and locomotor ability. Body structure/ function was evaluated by level of motor recovery with the Fugl-Meyer Scale - LL section ${ }^{11}$. The scale ranges from 0 to 34 with score 34 reflecting normal movement. Spasticity of hip adductors, knee extensors, soleus and gastrocnemius was evaluated using the Modified Ashworth Scale (MAS) ${ }^{12}$. Levels range from 0 to 4 , where 0 represents no increase in muscle tone and 4 indicates that the joint was rigid in flexion or extension. Positions used for spasticity evaluation were described by Blackburn et al. ${ }^{13}$. Mobility and balance were evaluated by the Timed Up and Go test (TUG) ${ }^{14,15}$. In this test, the individual is seated in a chair with armrests, and the time taken to stand up, walk forward three meters and return to the seated position is measured. Finally, the overground 10 -meter walking speed test ${ }^{16,17}(10 \mathrm{mWT})$ was measured on the comfortable and maximum speeds.

\section{Dynamometric evaluation}

Before undertaking the test, the subjects were familiarized with the procedures and instruments.
A dynamometer (Oswaldo Filizola Ltda.) with capacity for $200 \mathrm{~N}$ (resolution of $1 \mathrm{~N}$ ) was used to measure applied force. According to Daubney and Culham $^{18}$, healthy individuals do not reach strength values that exceed $200 \mathrm{~N}$ when they exert a maximum isometric contraction of knee flexors with the hip positioned at $30^{\circ}$ of flexion, which was the limit of the dynamometer used in the present study. A band was fixed around the subject's ankle, and a rope connected it to the dynamometer, which was attached to an iron support fixed on the wall. The dynamometer was aligned to the extremity of the lower limb (LL), right at the top of the lateral malleolus, where the band was placed. A goniometer was used to place the individual in the right position. The subjects performed two knee flexor muscle strength tests with two different hip positions. The measurement of maximum voluntary isometric torque for knee flexor musculature consisted in the knee flexor muscles acting with the hip joint positioned in $90^{\circ}$ of flexion (position 1) and $0^{\circ}$ of flexion (position 2). The position to be tested was randomized as well as the LL to be tested - paretic and non paretic LL in the group with hemiparesis, and dominant and non dominant LL in the control group. For the position 1 (P1) measurement, the subjects were placed in the supine position, with hips and knees positioned at $90^{\circ}$ of flexion, the thigh and leg were supported on a wooden box and the foot was free. In the position 2 (P2) measurements, the subjects were placed in the prone position with the hip joint at $0^{\circ}$ of flexion and the knee joint at $90^{\circ}$ of flexion. The subjects were asked to perform a maximal isometric contraction, and to maintain it for 4 seconds (s), against a dynamometer resistance with the knee flexed for both hip positions. Consistent verbal reinforcement was provided during muscle contractions. The test with each LL in each of the hip joint positions was repeated 3 times, and the mean of the three repetitions was obtained. The subjects were given 30 minutes to rest between each hip joint position test, and 2 minutes between each trial with the same LL.

\section{Data analysis}

The product of the force $(\mathrm{N})$ and the distance between the lateral malleolus (point of force application) and the knee joint was calculated as the knee flexion torque $(\mathrm{Nm})$. The values obtained were used to define the maximum isometric knee flexor muscles torque related to the hip joint position. To compare the decrease in force production due to hip position between subjects with hemiparesis and controls despite the presence of paresis, we calculated 
the ratio between knee flexor torque with the hip at $0^{\circ}$ and knee flexor torque with the hip at $90^{\circ}$, and it was called Hip $0^{\circ} / \mathrm{Hip} 90^{\circ}$ ratio. This ratio represents the decrease in knee flexor strength when the hip is extended and the hamstring muscles shortened, compared to a position when the hip was flexed and the hamstring muscles lengthened.

\section{Statistical analysis}

To evaluate the effect of hip position considering the absolute values of knee flexor torque within each group, we compared the knee flexor torque using twoway ANOVA, having as factors lower limb dominant and non-dominant (for control) or paretic and non paretic (for persons with hemiparesis) and position (hip at $0^{\circ} \times$ hip at $90^{\circ}$ ). To evaluate if the decrease in knee flexor torque due to hip position was different in the paretic limb compared to the non-paretic and control limbs, we compared the ratio of knee flexor torque hip $0^{\circ}$ /hip $90^{\circ}$ between lower limbs. Given that the paretic and non-paretic lower limbs of controls can be dominant or non-dominant and no difference is expected to be seen between limbs in controls, the data of both lower limbs (dominant and non-dominant) of controls were collapsed for comparisons with subjects with hemiparesis. Thus, the calculated ratio (Hip $0^{\circ} / \mathrm{Hip} 90^{\circ}$ ratio) was compared between paretic (P) and non-paretic (NP) lower limbs for individuals with hemiparesis and a mean of both lower limbs of controls (CTL) using one-way ANOVAs with Tukey's HSD as posthoc. The results are shown as means and standard deviation of scores, with a significance level $\mathrm{p}<0.05$. Also, we show the effect size $(\eta)$ of differences between the ratios.

\section{Results}

All participants had mild to moderate lower limb impairments (Fulg-Meyer ranged from 21 to 31), spasticity test scored 2 or less in knee extensors and ankle plantiflexors, except for one subject who scored 3. All participants took 20 seconds or less to complete the TUG, indicating that they had little problem with balance. Comfortable and fast walking speeds ranged from 0.48 to $1.25 \mathrm{~m} / \mathrm{s}$ and from 0.62 to $1.66 \mathrm{~m} / \mathrm{s}$, respectively. Five subjects with hemiparesis had moderate deficits in gait speed (comfortable walking speed ranging from 0.30 to $0.72 \mathrm{~m} / \mathrm{s}$ ) an the others had mild deficits (comfortable walking $\geq 0.72 \mathrm{~m} / \mathrm{s}$ ) ${ }^{16}$. At fast walking speeds, they have increased $25 \pm 11 \%$ from their comfortable speed (Table 1).

Despite these impairments, all subjects were able to exert force against the dynamometer with their knee flexed at $90^{\circ}$ in both hip $(\mathrm{H})$ positions (Position $1-\mathrm{H}$ at $90^{\circ}$ and Position $2-\mathrm{H}$ at $0^{\circ}$ ) with their paretic lower limb. All subjects with hemiparesis, except for one in the non paretic lower limb showed a decrease in knee flexion force production when the hip was in extension (Figure 1A). The mean absolute knee flexion torque was lower in the paretic limb compared to the non-paretic limb (ANOVA main factor lower $\operatorname{limb} \mathrm{F}_{1,18}=6.86 ; \mathrm{p}=0.02$ ) and decreased significantly when the hip was in the extended position (Position $2-\mathrm{H}$ at $0^{\circ}$ ) in both lower limbs (ANOVA main factor position $\left.\mathrm{F}_{1,18}=37.95 ; \mathrm{p}<0.001\right)$. The decrease in their

Table 1. Demographic and clinical data.

Control $(\mathrm{n}=10) \quad$ Hemiparetic $(\mathrm{n}=10)$

Persons with hemiparesis gender (n, \%)

\section{Male}

Female

Side of lesion (n, \%)

Right

Left

Months from stroke onset (mean, SD)

Clinical tests

LL Fugl-Meyer score (34)

TUG test (s)

$10 \mathrm{mWT}$ comfortable pace $(\mathrm{m} / \mathrm{s})$

$10 \mathrm{mWT}$ maximum pace $(\mathrm{m} / \mathrm{s})$
8

2

$80 \%$

$20 \%$
8

2

5

5

63

26

14

0.76

1.02
$80 \%$ $20 \%$

$50 \%$ $50 \%$

$\mathrm{LL}=$ lower limb; $\mathrm{TUG}=$ timed up \& go test $; 10 \mathrm{mWT}=$ ten meter walking test. 

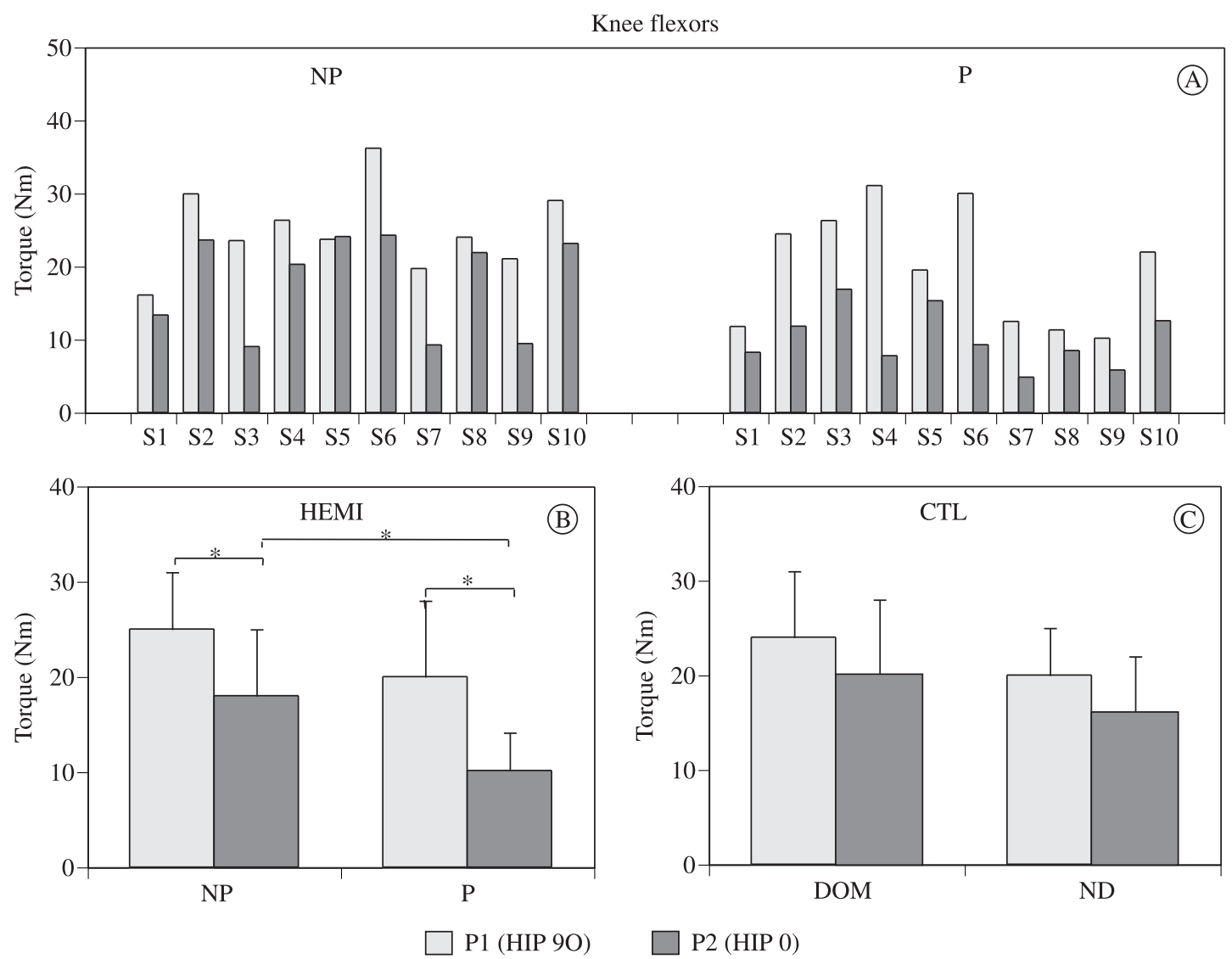

Figure 1. Comparison between knee flexor torque in P1 - hip placed at $90^{\circ}$ (open bars) and $\mathrm{P} 2$-hip placed at $0^{\circ}$ (filled bars). A) Nonparetic (NP) and paretic (P) lower limb for individual subjects (S). Data are arranged according to walking severity. B) Group mean (SD) values of knee flexion torque for subjects with hemiparesis (HEMI) for the non-paretic (NP) and paretic (P) lower limbs. C. Group mean (SD) values of knee flexion torque for control subjects (CTL) for the dominant (D) and non-dominant (ND) lower limbs. The asterisk below the horizontal bar indicates a significant difference between positions at the $\mathrm{p}<0.05$ level.

knee flexion force in $\mathrm{P} 2$ compared to $\mathrm{P} 1$ was $~ 45 \%$ and $\sim 30 \%$ respectively in the paretic and non-paretic LL in subjects with hemipareris (Figure 1B).

Controls tended to decrease their maximum voluntary knee flexion torque when comparing Position 2 to Position 1 (ANOVA main factor position $\mathrm{F}_{1,18}=4.18 ; \mathrm{p}=0.056$ ), with no significant differences between the dominant and non-dominant LL (11\% decrease in force production due to hip position for the dominant LL and 14\% decrease for the nondominant LL).

The comparison of the Hip $0^{\circ} / \mathrm{Hip} 90^{\circ}$ ratio between subjects with hemiparesis and controls showed that the ratio was different between lower limbs (one-way ANOVA $F_{2,29}=4.29 ; \mathrm{p}=0.02 ; \eta=0.24$ ). The Tukey post-hoc showed that the difference was between the paretic lower limb of subjects with hemiparesis compared to controls (Figure $2 ; \mathrm{p}=0.02$; $\eta=0.29$ ).

\section{Discussion}

Our results showed that knee flexion strength was dependent on hip position for both healthy age matched controls and individuals with hemiparesis. Although this has been shown previously ${ }^{4,19}$ for these two populations separately, a new finding is that the ratio of knee flexors $\mathrm{H} 0^{\circ} / \mathrm{H}^{\circ} 0^{\circ}$ is lower on the paretic LL of subjects with hemiparesis compared to controls. Previous studies did not compare the decrease in isometric knee flexion torque between subjects with hemiparesis and healthy controls. This ratio represents the decrease in knee flexor strength when the hip is extended, that is, when the muscled is in a shortened position, compared to a position when the hip was flexed. In our study, the ratio of knee flexor torque $\mathrm{H} 0^{\circ} / \mathrm{H}^{\circ} 0^{\circ}$ in paretic lower limbs was different from this ratio in aged matched controls. In agreement with results from a previous study by Bohannon ${ }^{10}$, which comparing the ratio of 


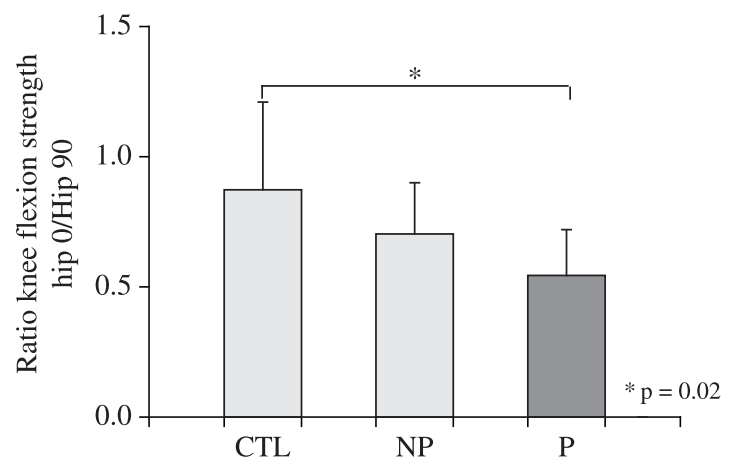

Figure 2. Comparison between ratios of knee flexor torque (knee flexors torque with hip at $0^{\circ} / \mathrm{knee}$ flexors torque with hip at $90^{\circ}$ ) between controls (CTL), non-paretic (NP), and paretic (P) LL for subjects with hemiparesis.

supine-to-sitting knee flexion torque between paretic and non-paretic lower limbs in a sub-acute group of subjects after stroke, despite different values of ratio, the statistics test did not show a significant difference between paretic and non-paretic limbs in subjects with hemiparesis.

The fact that maximum isometric force depends on muscle length has been well described in the literature ${ }^{20}$, but this fact alone does not explain the greater decrease in force production in the paretic lower limb compared to controls in our study. Muscle weakness, or the inability to generate normal levels of force, is a common consequence of stroke and has clinically been recognized as one of the limiting factors in physical function in the motor rehabilitation of stroke persons with hemiparesis ${ }^{19}$. Possible factors contributing to muscle weakness in the lower limbs following stroke include decreased number of functioning motor units, disrupted recruitment order of motor units ${ }^{21}$, and decreased motor unit firing rate ${ }^{22}$ in addition to muscle atrophy following disuse ${ }^{23}$. Considering that we used the ratio to compare lower limbs, we can assume that this decreased force production in the paretic LL still cannot be explained simply by muscle weakness following stroke.

Weakness dependent on joint position in paretic LLs can be detected in a largely used clinical test that evaluates motor recovery after stroke, the Fugl-Meyer Assessment $\mathrm{Scale}^{24}$. A recent study showed that in the sub-test "voluntary movement independent of synergy" of this scale, which evaluates the ability of flexing the knee in a standing position with the hip positioned at $0^{\circ}$, more than 40 out of 59 patients scored zero (unable to do the movement), indicating that this is a relevant clinical issue ${ }^{25}$.
In conclusion, in the present study, we found that there is a significant difference between the hip $0^{\circ} \%$ hip $90^{\circ}$ ratio of knee flexion torque in paretic LLs when compared to controls. That greater weakness dependent on joint position in individuals with hemiparesis following stroke may possibly be influenced by the presence of other factors beyond muscle length. The clinical implication of these findings is that more attention should be given to muscle strengthening exercises on lower limbs, placing particular emphasis on the strengthening exercises at short muscle lengths.

\section{References}

1. Katz RT, Rymer WZ. Spastic hypertonia: mechanisms and measurement. Arch Phys Med Rehabil. 1989;70(2):144-55. PMid:2644919.

2. Dewald JP, Pope PS, Given JD, Buchanan TS, Rymer WZ. Abnormal muscle coactivation patterns during isometric torque generation at the elbow and shoulder in hemiparetic subjects. Brain. 1995;118 (Pt 2):495-510. PMid:7735890. http://dx.doi.org/10.1093/brain/118.2.495

3. Ada L, Canning CG, Low S-L. Stroke patients have selective muscle weakness in shortened range. Brain. 2003;126(Pt 3):724-31. PMid:12566292. http:// dx.doi.org/10.1093/brain/awg066

4. Lunnen JD, Yack J, LeVeau BF. Relationship between muscle length, muscle activity, and torque of the hamstring muscles. Phys Ther. 1981;61(2):190-5. PMid:7465621.

5. Mohamed O, Perry J, Hislop H. Relationship between wire EMG activity, muscle length, and torque of the hamstrings. Clin Biomech (Bristol, Avon). 2002;17(8):569-79. PMid:12243716.

6. Koo TK, Mak AF, Hung LK, Dewald JP. Joint position dependence of weakness during maximum isometric voluntary contractions in subjects with hemiparesis. Arch Phys Med Rehabil. 2003;84(9):1380-6. PMid:13680578. http://dx.doi.org/10.1016/S0003-9993(03)00238-7

7. Mercier C, Bertrand AM, Bourbonnais D. Differences in the magnitude and direction of forces during a submaximal matching task in hemiparetic subjects. Exp Brain Res. 2004;157(1):32-42. PMid:14985898. http://dx.doi. org/ 10.1007/s00221-003-1813-X

8. Ellis MD, Holubar BG, Acosta AM, Beer RF, Dewald JPA. Modifiability of abnormal isometric elbow and shoulder joint torque coupling after stroke. Muscle Nerve. 2005;32(2):170-8. PMid: 15880629 PMCid:PMC2847894. http://dx.doi.org/10.1002/ mus.20343

9. Lum PS, Burgar CG, Shor PC. Evidence for strength imbalances as a significant contributor to abnormal synergies in hemiparetic subjects. Muscle Nerve. 2003 fev;27(2):211-21. PMid:12548529.

10. Bohannon RW. Decreased isometric knee flexion torque with hip extension in hemiparetic patients. Phys Ther. 1986;66(4):521-3. PMid:3960978. 
11. Michaelsen SM, Rocha AS, Knabben RJ, Rodrigues LP, Fernandes CGC. Translation, adaptation and inter-rater reliability of the administration manual for the FuglMeyer assessment. Rev Bras Fisioter. 2011;15(1):80-8. PMid:21519719. http://dx.doi.org/10.1590/ S1413-35552011000100013

12. Bohannon RW, Smith MB. Interrater reliability of a modified Ashworth scale of muscle spasticity. Phys Ther. 1987;67(2):206-7. PMid:3809245.

13. Blackburn M, van Vliet P, Mockett SP. Reliability of measurements obtained with the modified Ashworth scale in the lower extremities of people with stroke. Phys Ther. 2002;82(1):25-34. PMid:11784275.

14. Podsiadlo D, Richardson S. The timed "Up \& Go": a test of basic functional mobility for frail elderly persons. J Am Geriatr Soc. 1991;39(2):142-8. PMid:1991946.

15. Faria CD, Teixeira-Salmela LF, Silva EB, Nadeau S. Expanded timed up and go test with subjects with stroke: reliability and comparisons with matched healthy controls. Archives of Phys Med Rehabil. 2012;93(6):1034-8. PMid:22381595. http://dx.doi.org/10.1016/j. apmr.2011.11.025

16. Salbach NM, Mayo NE, Higgins J, Ahmed S, Finch LE, Richards CL. Responsiveness and predictability of gait speed and other disability measures in acute stroke. Arch Phys Med Rehabil. 2001;82(9):1204-12. PMid:11552192. http://dx.doi.org/10.1053/apmr.2001.24907

17. Nascimento LR, Caetano LCG, Freitas DCMA, Morais TM, Polese JC, Teixeira-Salmela LF. Different instructions during the ten-meter walking test determined significant increases in maximum gait speed in individuals with chronic hemiparesis. Rev Bras Fisioter. 2012;16(2):122-7. PMid:22378478. http://dx.doi.org/10.1590/ S1413-35552012005000008

18. Daubney ME, Culham EG. Lower-extremity muscle force and balance performance in adults aged 65 years and older. Phys Ther. 1999;79(12):1177-85. PMid:10630286.
19. Bourbonnais D, Vanden Noven S. Weakness in patients with hemiparesis. Am J Occup Ther. 1989;43(5):313-9. PMid:2655457. http://dx.doi.org/10.5014/ajot.43.5.313

20. Rassier DE, MacIntosh BR, Herzog W. Length dependence of active force production in skeletal muscle. J Appl Physiol. 1999;86(5):1445-57. PMid:10233103.

21. McComas AJ, Sica RE, Upton AR, Aguilera N. Functional changes in motoneurones of hemiparetic patients. J Neurol Neurosurg Psychiatry. 1973;36(2):183-93. PMid:4350702 PMCid:PMC1083552. http://dx.doi. org/10.1136/jnnp.36.2.183

22. Tang A, Rymer WZ. Abnormal force--EMG relations in paretic limbs of hemiparetic human subjects. J Neurol Neurosurg Psychiatry. 1981;44(8):690-8. Pmid:7299407. http://dx.doi.org/10.1136/jnnp.44.8.690

23. McComas AJ. Human neuromuscular adaptations that accompany changes in activity. Med Sci Sports Exerc. 1994;26(12):1498-509. PMid:7869885.

24. Fugl-Meyer AR, Jääskö L, Norlin V. The post-stroke hemiplegic patient. II. Incidence, mortality, and vocational return in Göteborg, Sweden with a review of the literature. Scand J Rehabil Med. 1975;7(2):73-83. PMid:1162302.

25. Crow JL, Harmeling-van der Wel BC. Hierarchical properties of the motor function sections of the Fugl-Meyer assessment scale for people after stroke: a retrospective study. Phys Ther. 2008;88(12):1554-67. PMid:18927197. http://dx.doi.org/10.2522/ptj.20070186

\section{Correspondence}

\section{Stella Maris Michaelsen}

Universidade do Estado de Santa Catarina Centro de Ciências da Saúde e do Esporte Programa de Pós-graduação em Ciências do Movimento Humano Rua Pascoal Simone, 358, Coqueiros CEP 88080-350, Florianópolis, SC, Brasil e-mail: michaelsenstella@hotmail.com 